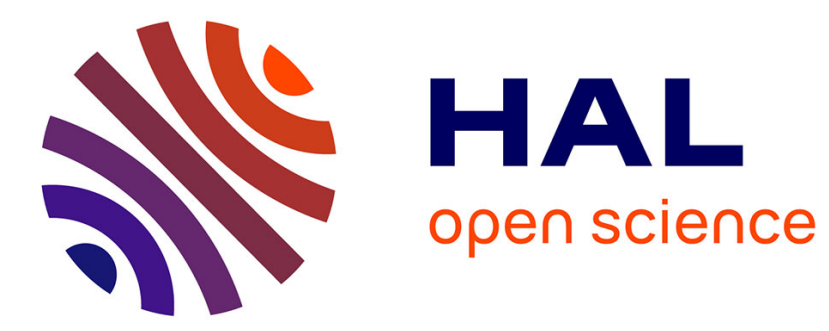

\title{
Toward an systemic navigation framework to integrate sustainable development into the company
}

Feng Zhang, Maud Rio, Romain Allais, Peggy Zwolinski, Tatiana Reyes, Lionel Roucoules, Eunika Mercier Laurent, Nicolas Buclet

\section{- To cite this version:}

Feng Zhang, Maud Rio, Romain Allais, Peggy Zwolinski, Tatiana Reyes, et al.. Toward an systemic navigation framework to integrate sustainable development into the company. Journal of Cleaner Production, 2013, 54, pp.199-214. 10.1016/j.jclepro.2013.03.054 . hal-01088221v2

\section{HAL Id: hal-01088221 \\ https://hal.science/hal-01088221v2}

Submitted on 27 Nov 2014

HAL is a multi-disciplinary open access archive for the deposit and dissemination of scientific research documents, whether they are published or not. The documents may come from teaching and research institutions in France or abroad, or from public or private research centers.
L'archive ouverte pluridisciplinaire HAL, est destinée au dépôt et à la diffusion de documents scientifiques de niveau recherche, publiés ou non, émanant des établissements d'enseignement et de recherche français ou étrangers, des laboratoires publics ou privés. 


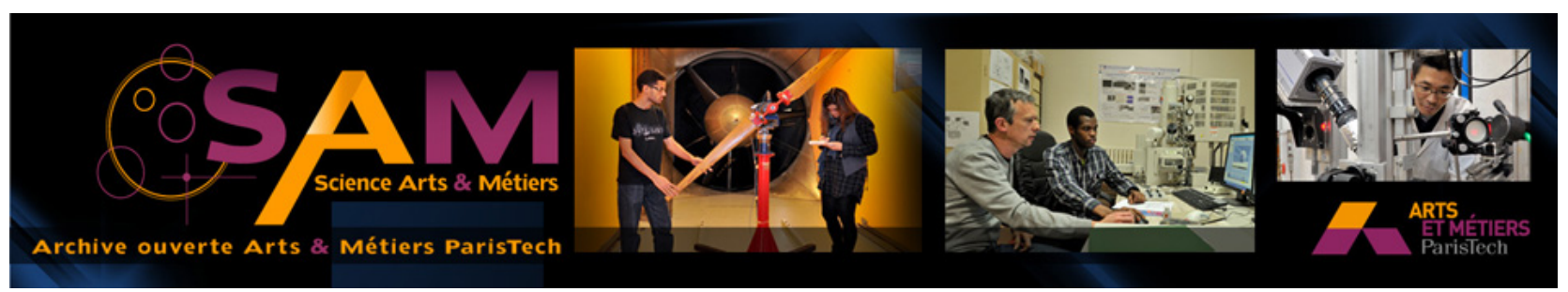

\section{Science Arts \& Métiers (SAM)}

is an open access repository that collects the work of Arts et Métiers ParisTech researchers and makes it freely available over the web where possible.

This is an author-deposited version published in: http://sam.ensam.eu

Handle ID: .http://hdl.handle.net/10985/9007

\section{To cite this version :}

Feng ZHANG, Maud RIO, Romain ALLAIS, Peggy ZWOLINSKI, Tatiana REYES, Lionel ROUCOULES, Eunika MERCIER LAURENT, Nicolas BUCLET - Toward an systemic navigation framework to integrate sustainable development into the company - Journal of Cleaner Production - Vol. 54, p.199-214 - 2013 


\title{
Toward an systemic navigation framework to integrate sustainable development into the company
}

\author{
Feng Zhang ${ }^{\mathrm{a}, *}$, Maud Rio ${ }^{\mathrm{b}, \mathrm{c}}$, Romain Allais ${ }^{\mathrm{b}, \mathrm{c}}$, Peggy Zwolinski ${ }^{\mathrm{a}}$, Tatiana Reyes Carrillo ${ }^{\mathrm{b}}$, \\ Lionel Roucoules ${ }^{c}$, Eunika Mercier-Laurent ${ }^{\mathrm{e}}$, Nicolas Buclet ${ }^{\mathrm{d}}$ \\ ${ }^{a}$ Grenoble INP, G-SCOP Laboratory, 46 Avenue Félix Viallet, 38031 Grenoble, France \\ ${ }^{\mathrm{b}}$ University of Technology of Troyes, CNRS, CREIDD, 12 rue Marie Curie, 10010 Troyes, France \\ ${ }^{\text {c } A r t s ~ e t ~ M e ́ t i e r s ~ P a r i s T e c h, ~ C N R S, ~ L S I S, ~} 2$ cours des Arts et Métiers, 13617 Aix-en-Provence, France \\ ${ }^{\mathrm{d}}$ University Grenoble Alpes, CNRS - UMR Pacte, 14 bis, Avenue Marie Reynoard, 38100 Grenoble, France \\ ${ }^{\mathrm{e}}$ Groupe MODEME, Centre de Recherche IAE, Université Lyon 3, 6 Cours Albert Thomas, 69355 Lyon, France
}

Keywords:

Sustainable strategy

Environmental management

Decision-making

Eco-design

\begin{abstract}
A B S T R A C T
In a very uncertain and competitive economy, companies have to cope with external constraints such as environmental and social issues, to gain competitive advantage. Over the last thirty years, numerous initiatives have appeared to deal with socio-environmental issues. However, contexts are complex and dynamics. Many authors therefore point out the need to establish a systemic perspective in order to improve the integration of sustainable issues into all company activities: from strategic decision-making to the end of the project. In addition, companies need to reinforce the relationship between general corporate development and eco-design activities. Based on literature review, this paper assumes that the integration of sustainability can be improved by developing a coherent and system approach between strategic, tactical and operational levels. The authors have chosen to demonstrate this assumption by targeting the environmental aspect of sustainability as a first step of their overall research.

In this view, this paper proposes a navigation system composed of three modules: strategic, tactical and operational. This navigation system provides some pragmatic roadmaps for integrating environment into the company. Each module is linked to the others by the use of appropriate metrics. Bottom-up and top-down or middle-to-sides strategies are fully supported.

To test this proposal, the navigation system is experimented retrospectively into an industrial process from the textile industry. The comparison between the initial situation and the experimental results allows authors to highlights potential environmental improvements. Some recommendations are made to challenges companies to use this navigation system, which argues in favor of environmental improvements.
\end{abstract}

\section{Introduction}

The growing attention given to sustainable development is encouraging companies to integrate sustainable issues into their activities. To increase the performance of this integration, some literature point out that sustainable aspects should be embedded at all corporate hierarchical levels, from global strategic decisions by top management, through planning and organization by tactical management, to daily engineering and production activities of the operational area (Hallstedt et al., 2010; IMES, 2010; Reyes et al.,

\footnotetext{
* Corresponding author.

E-mail address: fengeric.zhang@gmail.com (F. Zhang).
}

2007). Fig. 1 illustrates the interactions between "decision makers" involved at the different hierarchic levels.

Therefore sustainable strategy cannot be considered an independent issue: it must be integrated into corporate global development strategy. This integration needs to support sustainable goals to be in line with other existing global corporate tendencies and constraints. To do so, the company needs to carefully and reasonably break down "sustainability" into several actions or attributes to help its comprehension (Hallstedt et al., 2010). But considering the growing number of existing sustainable methods and tools, the identification and placement of suitable action plans is becoming more and more complex (Bovea and Pérez-Belis, 2012; Pardo et al., 2011). Moreover, in order to measure environmental contributions and encourage closed-loop continuous improvements, the company 


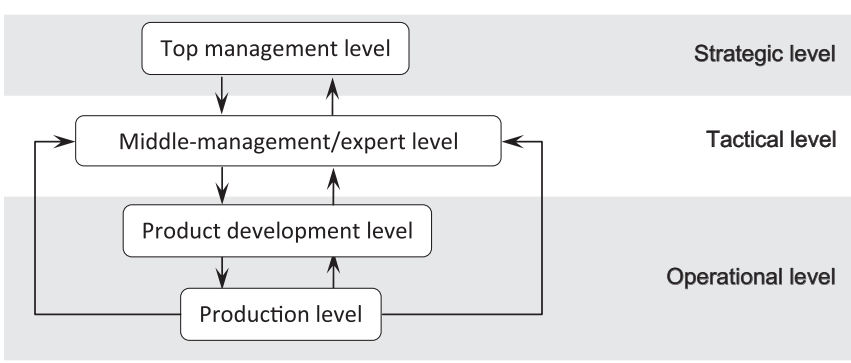

Fig. 1. Interactivity and coherence between hierarchical corporate levels for environmental management.

needs to evaluate how the benefits of all implemented sustainable activities contribute to corporate global development (Hallstedt et al., 2010).

However, in practice, the integration of sustainable issues faces some difficulties. Some literature suggest that one of the principal barriers is the lack of an existing systemic approach. This approach would provide a global overview in line with the reel structure needed to deal with sustainability; the company should not only focus on product level, but also on the strategic or tactical level ( $c f$. example of contribution in this view: (Hallstedt et al., 2010; Johnson and Scholes, 2008; De Bakker et al., 2002; Erlandsson and Tillman, 2009). In order to contribute to resolve this problem, a French national research project, "Convergence", was launched. This project, founded by the French National Research Agency (ANR), is associated with four French universities and two industrial partners: the French Textile and Apparel Institute (IFTH) and Quiksilver $^{\odot}$. The final objective of the project is to determine whether sustainable integration could be improved by better cooperative circulation between the different company levels (strategic, tactical and operational), and to propose a navigationbased approach to support this improvement. In this approach, the strategic level assists "top managers" who define the corporate strategic goals that will create multi-values for all stakeholders. In order to respond to strategic goals, the tactical level analyzes and organizes the corporate material and immaterial resources (for example: cost, knowledge, Human resource, Relationship with stakeholders or organization.) and develops an efficient and implementable roadmap. This matches the strategic goals with specific technological solutions and identifies related "activity tables/chains" to help meet these goals. Lastly, the operational level supports deployment of the process in the company in accordance with the tactics (and tools) chosen.

Authors therefore assumes that the integration of sustainability into the company can be improved by developing a holistic, overall and system approach to creating interactivity and coherence between these three complementary levels ( $c f$. Fig. 1). In this research, "Holistic" means that the approach is part of a global meta-system and is not disconnected from its contexts (economic, political, environmental and social). "Overall" means that sources flows (material and immaterial) and reservoirs of value (such as people, knowledge, process) are all taken into account. Finally, "System" means that every node of the system supports dynamic interactions with the whole system (Mercier, 2009).

As a first step to argue toward this assumption, authors have chosen to only deal with the environmental issue of sustainability. Therefore the level of complexity of the demonstration provided in the paper makes possible to tackle the structure of the research proposal in an understandable manner. However, some aspects such as social issues, human health and protection are part of the demonstration at strategic level. These will be addressed at tactical and operational levels in further research.

\section{State of the art}

\subsection{Current approach to sustainable strategy}

How can top managers build and deploy a sustainable strategy which will drive their organization to a desired future for the company and its stakeholders?

Corporate social (or societal) responsibility (CSR) can be defined as a corporate contribution to sustainable development, and the related "overall performance" may evaluate achievement. This stakeholder-centered vision is an alternative to the traditional vision which is only responsible for financial performance to the shareholder. Charreaux and Desbrières (2001) proposed an enlarged definition of value creation embedding the stakeholder value. The stakeholder-centered view of the company allows a reconsideration of value creation and value sharing in the company so that it is not merely oriented toward shareholders.

\subsubsection{Strategy and sustainable strategy}

Corporate strategy, in Porter's perspective (Porter E., 1979), becomes the art of positioning the company's activity in the best place on the value chain regarding competitors, and optimizing its added value. This vision of value creation is modeled on assembly lines. Despite their importance in the value-creation processes, assembly lines are no longer the primary mode by which overall value is created along the value chain: like technological innovation, customer relations, are determining factors of the overall valuecreation system (Normann and Ramirez, 1994). In fact, value creation has been evolving in line with economic models from the early industrial revolution to the latest developments such as the service economy (Buclet, 2011a) or collaborative consumption models (Botsmann and Rogers, 2011). In our current economy, fundamental resources no longer work organization and marketing, but knowledge and relationship (Normann, 1993). Economic models evolve and make value creation models evolve with them, from a chain of added value (Porter, 1979) to a complex value network (Allee, 2000). In the current knowledge-based economy, one major strategic challenge is how to reconfigure a company's whole business, starting from the value creating system itself. Stakeholders are coproducers of value and company strategy is based on the constant reconfiguration of interactions between actors (Allee, 2000; Normann and Ramirez, 1994). The value chain has mutated into the value constellation. These days, organizational innovation is a key to success in an uncertain and competitive economy. In this approach, (Normann, 1993) defines corporate strategy as the art of creating value.

Johnson and Scholes (2008) defined corporate strategy as the combination of strategic analysis, strategic choice and strategic implementation. In a sustainable perspective, integration of stakeholders' needs (and expectations) into corporate strategy is a key point for any corporate sustainable process (ISO 26000). Sustainable strategy can be understood as the creation of value to answer stakeholders' expectations and needs (this statement is detailed in chapter 2.1.3) if this does not conflict with sustainability principles (detailed in chapter 2.1.2).

\subsubsection{Sustainability principles}

Hallstedt et al. (2010) proposed a review of sustainability integration methods, tools and concepts in strategic decision systems. Different approaches are cited, including forecasting, that uses current trends to define a likely future. However, in uncertain and very fluctuating contexts, it is risky to predict the future. The backcasting approach freezes the future in a desirable state (success) and then creates a pathway to reach this desired future from the present. Nevertheless, it can be hazardous to create a consensus 
on a desired future, given the divergent expectations of multiple stakeholders. Consequently, the "framework for strategic and sustainable development" (FSSD), developed by Azar et al (1996) is an open-ended and non-prescriptive framework that proposes some sustainability principles. Three of these four principles are connected to environment. First and second principles concern substance flows from different origins (lithosphere and society) to ecosphere. The third principle is about the protection of ecosphere production capacity and the protection of biodiversity. The fourth principle is about resource use efficiency regarding human needs. These four principles are mainly oriented to environmental issues. Buclet (2011b) proposed a further three principles of coordination between actors to modify the current inconsistent paradigm with sustainability. First, the proximity principle between the decision level and the level affected by these decisions, which is divided into physical, organizational and institutional proximity. The capability principle aims at respecting and developing the individual's ability to meet its own goals. And the participative democracy principle enables a balance between liberty and collective constraints and between individual and common interests.

\subsubsection{Stakeholders}

The way in which stakeholders are identified and integrated into the strategic analysis is decisive in defining sustainable strategies.

Freeman defined stakeholders as any group or individual who can affect or be affected by the achievement of the organization's objectives (Freeman, 1984). This broad definition addresses the parameter of who should be considered as stakeholders. Mitchell et al. (1997) proposed a partition and classification of stakeholders based on three criteria: urgency, legitimacy and power. He identifies 8 different types of stakeholder ranging from nonstakeholder to definite stakeholder. In fact, traditionally, stakeholders were selected with regard to their proximity to the economic activity of the company. Hillman and Klein (2001) underlined that the integration of stakeholders closest to the economic activities could improve economic performance. Bieker and Gminder (2001) proposed some visions of strategic orientations other than the profit-centered vision. The green case, in economic and social spheres, is dedicated to environmental protection. And the social case, in environmental and economic spheres, develops human rights. These alternative visions require the tools to control new objectives. In this research, the concept of overall performance comes from this new vision of the company.

\subsubsection{Overall performance and its evaluation}

Performance measurement of an industrial system is mainly about cost, quality and time. This measurement system is not relevant to manage the strategy to meet multiple stakeholders' needs. Overall performance is defined by Baret (2006) as the aggregation of economic, social and environmental performance. However Capron and Quairel (2006) underlines the lack of integration and balance between these three dimensions of sustainability given by the strategy definition. He qualifies this performance as a search for integration and equilibrium between the triple objectives of sustainability (economic, social and environmental). Overall performance evaluation is a multi-domain enlarged management control system that measures the company's economic, social and environmental behavior. These performance evaluations are directed at multiple stakeholders with multiple objectives (Quairel, 2006).

\subsubsection{Performance measurement systems}

The Balanced Scorecard (BSC) (Kaplan and Norton, 2001) and its prolongation for CSR (Sustainable Balanced Scorecard (Hockerts,
2001) and Total Balanced Scorecard (Supizet, 2002)) connect the financial performance and its drivers with a multi-perspective approach. Despite this balanced and multi-dimensional set of measures, these tools are dedicated to financial performance.

The performance prism Neely (2007) proposed a stakeholdercentered view of performance measurement. This approach focused on value creation for stakeholders. The central issue becomes the identification of stakeholders and understanding their expectations and needs (Neely, 2007). The author emphasized that his proposition does not assume that all stakeholders are equally important. From his point of view, consideration must be given to traditional stakeholders such as employees and suppliers. However it is clear that for most of the company, shareholders remain the most important stakeholders. He also noted that the only reason for an organization to have a strategy is to deliver value to some stakeholders.

To summarize, there is no shortage of different approaches and visions of the company to guide decision-makers through corporate strategy definition. The key point for sustainability is to identify stakeholders' needs and interests and to involve them in the decision-making process and activities. Therefore, performances of sustainable strategies have to be managed by using tools adapted to this approach.

\subsection{Current environmental tactical planning}

Although corporate strategy is generic, its applications are very diverse. To aid comprehension, environmental or green strategies should be carefully and reasonably broken down into several actions (Hallstedt et al., 2010). For some environmental actions, like entire life-cycle analysis, avoidance of hazardous materials and the environmental performance declaration, a vast range of environmental methods and related tools has been developed (Baumann et al., 2002; Brezet and Van hemel, 1997; Unger et al., 2008; Siegenthaler et al., 2005; Hallstedt et al., 2010). Nevertheless, in practice, the required competences and resources of each set of methods and tools are never uniform. In addition, the achievability of these requirements follows different action chains depending on corporate sources, the knowledge situation, corporate responsibility and various needs. Consequently, the growing number of environmental methods and tools and the complexity of corporate contexts are leading to a new challenge: depending on the corporate policy and the different contexts, how can we select and organize the deployment of suitable environmental methods and tools to build the sustainability of companies?

\subsubsection{The engineering evaluation of environmental methods and} tools

Unger et al. (2008) claimed that there is no uniform solution to selecting environmental methods and tools. Some criteria and evaluating characteristics have been indicated. Logically, first, criteria in the engineering category need to be considered. Baumann et al. (2002); Bovea and Pérez-Belis (2012) evaluated the environmental methods and tools by some common indicators: the contribution area, the life cycle aspect, when they might be integrated, the nature of the form of work and the results. Secondly, to complete the section, some operational criteria relying on the required resources are given. (Robèrt et al., 2002) set up a framework to identify environmental methods and tools according to corporate contexts and real needs. The Integrated Environmental Management System, published by US Environment Protection Agency (EPA), emphasizes that in the current corporate context, factors such as implementing cost, required time and competences need to be considered. Unger et al., (2008); Pardo, 2011) synthesized these characteristics as a "complexity" indicator for selection. 
Unlike classical engineering criteria, operational indicators, such ascost, time and complexity, are dynamically changeable. For two different companies, the characteristics of "complexity" of one method or tool may not always be the same. Although for one company, given the development of its competences and its financial situation, the "complexity" score will be movable and changeable. So the pure analysis of the "complexity" of environmental methods and tools, without analyzing the corporate context, is not enough to guide the company's selection. Wagner (2007) identified a lack of prioritization of supports for defining the sustainable aspects of each context and selecting suitable actions. Unger et al. (2008) highlighted the need to consider some operational indicators, such as real complexity, operational period, resource availability and current cultural context. In previous research, (Zhang, 2011) focused on the fact that the evaluation mechanism may prioritize environmental methods and tools by the gap between the method's needs and the current context of the resource. This mechanism could therefore ensure a dynamic evaluation through corporate development. However Unger et al. (2008) did not present any solution for the integration of these dynamic factors as regards the project context, and (Zhang, 2011) only noted a global framework, without the details of the score judgment and use scenarios.

\subsubsection{The implementable evaluation of environmental methods and tools}

As mentioned earlier, the industrial context affects the selection of environmental methods and tools. So logically, the previous and current methods or tools implemented could also influence the new selection, because they will have modified the competences, expertise, software and informatics database of the company. For example, the result of product "recyclability" is a condition for launching the product end-of-life improvement. So if end of life improvement is one of the final strategic objectives of this company, calculation of the "recyclability" of the current product might be a stage in preparing this condition. Therefore a new challenge for environmental method or tool selection would appear: how can the company prepare a long-term implementation plan in its early stage that identifies a trajectory of achievement with a series of environmental methods and tools which step by step, have the capacity to continually modify the selecting conditions?

In addition, the above paragraph only presents the problem of the selection of one suitable environmental method or tool to respond to one strategic requirement. However, in practice, the company needs to deal with several strategic objectives and launch several related eco activities at the same time. (Zhang, 2011) presented the same points through an industrial review of the corporate eco-design program of some electric and electronic companies. This practical need leads to an additional challenge regarding the selection of environmental methods or tools. How to optimize the environmental methods network in the company? In other words, does an implementable method affect the dynamic operational context when selecting another parallel method? Zhang and Zwolinski (2012) pointed out that the identification of an environmental-methods or tools group should consider three coherences: coherence between the selected methods; coherence between different corporate functions, and coherence with corporate global development. Focusing on methods, the coherence requires two types of analysis: first, an analysis of the sharability and co-operability of required information and resources among all selected environmental methods. Sharability means that several resources can be used by different methods or tools, and co-operability presents the operational chain of the methods or tools, so that the outputs of some environmental activities can be used as the inputs of others. This analysis could dynamically evaluate the operational complexity of different method or tool groups, because the context and condition have been changed by an already-implemented method or tool. Secondly, this analysis focuses on trade-off risks which can be a source of confusion between the environmental targets (Zhang and Zwolinski, 2012; Byggeth and Hochschorner, 2006). A dynamic analysis should be launched to evaluate whether the selected methods could lead to this risk. Reyes et al. (2007) highlighted that this mechanism should be developed to analyze the relationship between different environmental methods and tools (series and parallel). Therefore Reyes et al. (2007) proposed a mechanism, the "Trojan horse" mechanism, involving some simple contexts and pre-defined scenarios of a trajectory to support small and medium-sized companies.

\subsubsection{The integration of selected environmental methods into the company}

Therefore the integration of environmental methods and tools into the company's activities will require some information and competences. In practice, the collection of this information, which brings together the required competences, needs real cooperation between different functions of the company (not only with the designer). Reyes et al. (2007); Pujari et al. (2004) proposed the degree of interface and coordination between different functions that determines the integration of environmental aspects into the company. Lakemond and Berggren (2006) also proposed that a multi-functional integration (such as: production, marketing, design) positively influences the quality of the final product. To integrate all selected methods and tools, a definition, such as the work flow, time for each activity, way of working, actors, cooperation and responsibility of each corporate function, needs to be identified at the start. Knight and Jenkins (2009) studied a company's R\&D process and proposed how eco-design techniques could be determined as being compatible with product development processes. However, this study has only analyzed some engineering constraints, without considering operational issues and integration solutions. In addition, the results are not easily usable in other situations (Pardo, 2011). Moreover, Bovea and Pérez-Belis (2012) classified and analyzed some environmental methods and tools, and pre-identified the operational timing of each during the product development process. This study could easily be extended to other types of environmental methods and tools, such as communication, purchasing and production tools.

To summarize this section, as regards the complex and dynamic corporate context, there is a lack of a global approach to identifying an achievable trajectory. This would optimize and organize the relationship between the selected environmental methods, and would aid coherence with the corporate strategy and other particular needs.

\subsection{Current approaches to integrate environmental issues during operational design process}

Can the selection of environmental methods or tools and required resources defined by tactic managers be effectively and operationally deployed during the design process? This question refers to the operational capability of current designers to collaborate with environmental designers within their related tools. This section therefore focuses on existing solutions for integrating the environmental parameter within existing activities, in the collaborative context of the design process.

The activity of designing is particularly complex, involving people, processes, activities, procedures, knowledge, tools and methods (Blessing and Chakrabarti, 2009; Roozenburg and Eekels, 


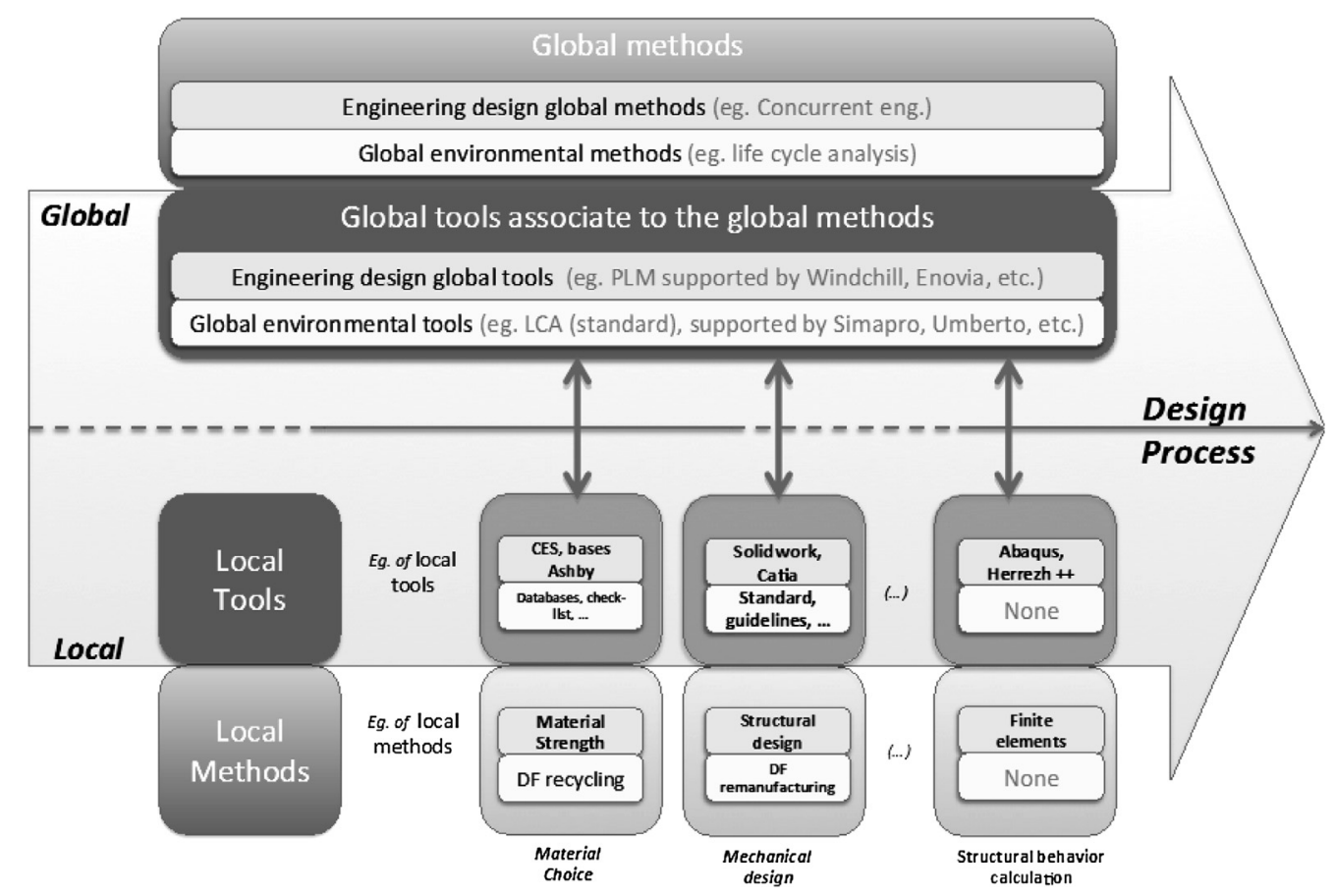

Fig. 2. Local and global organizational framework: a distinction between local product designers' activities and global environmental activity (transversal).

1995). Several authors have given definitions of stages and stakeholders (for instance, product designers, external experts, suppliers) involved in the design. As an example, Pahl and Beitz (1996) described the design stages, from product planning and clarifying the task, conceptual design and embodiment design to detail design. Each stage involves several stakeholders. They work on different tasks using their own tools or supports. However ISO Standard 14062: 2002 defines the "process" as a unit of correlated or interactive activities which transforms elements of input into elements of output. As a consequence, stakeholders need to communicate and interact together. Therefore, the design process is a collaborative process where product designers exchange and share limited and complementary resources. Their goal is single and common. ${ }^{1}$ Collaboration is structured by undefined tasks that are non-hierarchical and that go in multiple directions ( $\mathrm{Lu}$ et al., 2007).

\subsubsection{Local and global tools framework}

Considering the characteristics of the design process (a multitask, multi-domain and multi-activity process), Fig. 2 proposes a specific organization presenting environmental tools and methods along the design process: a local/global (transversal) framework (Rio et al., 2011a; Rio et al., 2011b).

- Global methods deal with transversal visions, such as life-cycle analysis. These methods require a global and transversal vision in order to deal with the collateral impacts of the various choices taken separately by local designers from different domains (such as industrial design choice, mechanical choice and material choice). They are supported by a wide variety of environmental tools, such as qualitative or quantitative, multicriteria as well as multi-impact tools (e.g. LCA).

\footnotetext{
${ }^{1}$ Collaboration differs from coordination and cooperation, in which stakeholders can have multiple, competing or private goals.
}

- Local methods are managed by identified and separate product design activities. "Design for X" methods for instance, are local methods. X refers to the specific local activity involved, supported by specific tools (such as CAD software for mechanical design activity for instance). Each local tool can be completed by a local integrated environmental module (for instance: the SolidWorks Sustainability module).

As shown in Fig. 2, this framework can be used to rank several local and global environmental (transversal) tools, supporting each activity along the design process. In addition, this framework supports the identification of local and global links between the environmental tools needed to support collaboration from the beginning until the end of the design process (symbolized by the arrows).

However in practice, these links are difficult to establish. For instance (Mougenot, 2008) raised the issue of the accessibility of tools in the early stages of the design process, because of the informal nature of the data. Vallet et al. (2010) highlighted the socio-cognitive issues of environmental tool appropriation by product designers. (Riel et al., 2010; Niemann et al. (2009) showed the difficulty in sharing knowledge and data related to a domain activity. Another example taken from the literature is the difficulty of tools to interoperate (Paviot, 2010). Interoperability is the capacity of two or more software or tools to exchange information. This latter issue is the subject of the following section.

\subsubsection{The interoperability issue between virtual product} development tools and environmental assessment tools

As seen in Fig. 2, the process involves multiple independent tools dealing with different data. As well as the product designer's tools, each environmental tool evolves separately and deals with continuously evolving knowledge. For instance, huge amounts of data are needed to conduct an LCA. However, Life Cycle Inventories (LCIs) are based on product nomenclatures. This facilitates data exchanges between the LCA tool and the Product Data Management 
system that gathers information about product nomenclature. In practice, several projects have been conducted to develop interoperable solutions between Life Cycle Assessment tools (not only LCA) or CAD - Computer Aided Design tools and PLM-Product Life cycle management systems.

First, a "specific LCA module" can be integrated into the CAD software: SolidWorks Sustainability Module for instance (developed by Dassault System) provides a simplified LCA based on GaBi LCA software developed by PE international. Another example of interoperability solutions can be illustrated by the Dassault System Workbench, which provides a set of integrated tools to support the integration of environmental concerns in a life-cycle product and company site perspective (a global IT approach, not restricted to performing an $\mathrm{LCA}^{2}$ ): the product $\mathrm{CAD}$, the plant $\mathrm{CAD}$, their specific substance traceability solution for REACH and RoHS certifications and with a third party of LCA tools (Theret et al., 2011). In this approach, the proposed data architectures are "based on a pivot or hub component interacting with all other applications". All data are centralized in an "Environmental Data Workbench", using a specific format (Theret et al., 2011). In other words, the interoperability between the eco-design tools and product designer's tools is supported by an integrative approach based on standards. Whereas in federative approaches (such as (Mathieux et al., 2007), which demonstrate federation between CAD and LCA tools and between PLM and LCA tools), data is not centrally duplicated. Information exchanges are "locally" defined between the target model (e.g. CAD Outputs) and the source model (e.g. LCA Inputs) (Rio et al., 2013).

In the computer sciences, integration and unification are both interoperability approaches using a standard format (such as STEP, $\mathrm{XML}$ ) to support data exchanges. In the case of unification, the product models are defined by semantic equivalences. Whereas in integrative approaches, each specific model is adapted to a standard model, and any modification of this standard leads to the modification of each model related to each tool. This is particularly time-consuming and inflexible in changing contexts.

As seen previously, eco-design is supported by various environmental tools. These tools are deployed according to the tactic defined by managers with regard to available resources. The selection of given tools depends on the context of the design process involved (Ex: type of product, type of method chosen, technology involved). Therefore:

- The structure of interoperability should be as flexible as possible (to be adaptable to changing contexts)

- The data exchanges between environmental tools and product designers' tools should be as dynamic as possible (excluding the systematic use of standards)

Iraqi et al. (2011, 2012) argue that interoperability supported by federative approaches provides more flexibility in company IT systems. Federation is based on a unique meta-meta-model. It means that any new model can be added by dynamic adjustment which makes it suitable for linking local and global environmental tools. (Mathieux et al., 2007) using federation, compares the efficiency of CAD data transfer into LCA tools, to PLM data transfer solutions. The authors argue that federation could improve cooperation between product designers and environmental engineers. They introduce potential gains regarding federation compared to integration: time, connection flexibility, capacity to avoid negative

\footnotetext{
${ }^{2}$ The authors of this research are currently working on how to integrate complementary eco-design tools, such as non-ecodesign expert tools (ECOFAIRE), or tools directed at mechanical engineering designers (MAICO/ATEP) (Theret et al., 2011).
}

environmental impacts as early as possible during the design process.

These above researches about federation present opportunities in terms of flexibility and adaptability improvements of local and global environmental designer's tools during the design process. Nevertheless, literature does not present any clear example of a wide variety of tools (not only LCA) that could be used along the design process in a federative approach, nor the possible connections between the various product designers' activities and the various environmental tools, in a systemic perspective of changing contexts (given by managers). Lastly, although federation shows great potential to improve the deployment of environmental tools on the operational level when designing products, there are still some weaknesses regarding the way of measuring this improvement in order to dynamically adjust operational-level resources to tactical and strategic levels (Rio et al., 2013).

\subsection{Collaboration among the entire company}

Some following literature point out that the deployment of sustainable issues needs a corporate life cycle that considers all relevant aspects of corporate daily routines. Yen and Yen (2012); Johansson (2002); MacDonald (2005) presented a clear strategic planning for sustainability plays a significantly role to pilot the environmental integration and drive the various development roadmap. Johansson (2002) summarized this issue by pointing out other major related success factors for integration of eco-design to take into account: an efficient internal management to identify the goals, methods/tools and develop the required competence, The collaboration among different functions, the strong relationship with all stakeholders and the motivation and communication to encourage the eco-innovation. De Bakker et al. (2002); Jorgensen (2008); Erlandsson and Tillman, 2009 presented a similar viewpoint. To improve the environmental aspects of the product, it is necessary to consider the global company objectives, the organizational aspects, the relationship with stakeholders, as well as competences and real design collaborative processes. The environmental improvement objectives involved at the strategic level should be fulfilled at product level. Conversely, objectives considered at product level might bring a visible influence from the operational level on strategic decisions.

Because of the needs of vast of information exchanges among multidisciplinary background, in order to avoid the misunderstanding and ensure the exchange efficiency among the entire company, (ISO 14001, 2004; EMAS, 2009) and some productoriented environmental management systems require a strong internal and external communication to measure the environmental impacts, to define the action plan, as well as to monitor the improving process. Hallstedt et al. (2010); Zhang and Zwolinski (2011) stated that a systemic framework with a uniform and optimized circulation of decision and data flows connecting various levels and functions is necessary to optimize sustainable integration. Wagner (2007); Ziegler and Nogareda (2009); Johnson and Scholes (2008) demonstrated also that the implementing environmental management system with a better circulative and collaborative aspects presents a positive effect exclusively on environmental process innovation.

Some approaches have been proposed to establish the circulation among entire company. Rocha and Silvester (2001) proposed a general framework to identify the relationship among strategic, managerial and operational level. Additional, he proposed 34 typical activities occurring at three different levels which need to consider some environmental aspects. Wagner (2007) formulated the related work flow in four phrases: the establishment of sustainable context; the exploration and definition of sustainability 
issues; the assessment of the best solution and its implementation; and managing the feedback.

Robèrt et al. (2002) proposed a uniform framework of Strategic Sustainable Development (SSD). This framework identified five steps: (1) the "System" step describes the general situation of the company, such as stakeholders, society, laws; (2) the "Success" step establishes its global socio-ecological sustainability; (3) the "Strategic guidelines" step identifies each investment and development decision to make the balance between environmental issues and global development needs; (4) the "Action" step organizes the implementable plan for each strategic decision; and (5) the "Tools" step selects suitable environmental methods and tools, and involves them in daily activities. This framework defines the architecture of the decisional information flows between different corporate levels. It successfully defines the general structure and global working flow. However, (Robèrt et al., 2002) does not provide the working details of each step to support the company in dealing with these topics. Lastly, the paper does not indicate the means and nature of the information transfers which occur between the two following steps.

Beside of above framework, there are some literature analyzed the details of decisional and executive flow for environmental aspects integration. The "Integrated Environmental Management System" (IEMS, 2000) published by EPA-Environment Protection Agency in 2001, proposed a systemic approach (nine modules and a series of methods) to ensure a complete integration of eco-design. This approach provides a rating evaluation method to define the strategic product objectives regarding eco-design. The method focuses on a detailed informational work flow throughout the entire company in order to realize strategic objectives and collect feedback to ensure continuous improvement. Zhang and Zwolinski (2011) also described a navigation system which provides a quantitative method and a more legible information transfer system. And finally, "Design for sustainability" (D4S) focuses on product innovation, and describes how to collaborate with stakeholders, from top managers to designer level, to ensure the efficiency of innovation.

In practice, Donnelly et al. (2006) presents a corporate approach of systemic eco-design management of the company "Lucent Technologies". Another example is the "ACADEMY" project (Airbus Corporate Answer to Disseminate Environmental Management sYstem), (Airbus, 2008) that has provided some practical experiences in using the environmental management approach, extended to the entire life cycle of the product. This system makes the balance between the global environmental management system and aspects related to eco-designing of products, entirely integrated into the company.

The study of the above propositions supports the identification of working details at each step. However firstly, these propositions focus solely on a product-oriented approach. Strategic objectives are only localized in product characteristics. Secondly, the systems proposed do not consider the relationship between eco-design activities, nor the need for a global corporate development. Regarding the hypothesis of this paper, this relationship is a critical point in encouraging sustainable integration in the company. Lastly, although the "ACADEMY" project provided some examples of combining these two issues, the results are difficult to extend to other companies.

\subsection{Systemic navigation framework specifications}

According to the above states of the art regarding environmental integration into the entire company, this integration needs a systemic approach to be supported. However, there are several major issues between the ideal integration model and current company results. At strategic level, the company needs a legible and quantitative method to evaluate its global situation, including material resources and immaterial capitals. Another issue has been identified regarding the relationship between the global objective of value creation and the sustainable activities carried out in company (including environmental, social and cost considerations). At tactical level, a global approach is necessary to identify a sustainable trajectory (with a series of selected methods) depending on the strategic objectives and the complex and dynamic changeable corporate context. At operational level, dynamic and flexible information exchanges between product designers and environmental engineering tools are needed to effectively deploy the (eco-) design process as regards the available resources.

The last issue concerns the whole systemic approach. The above state of art demonstrated that a better circulation among different hierarchical levels (strategic level, tactic level and operational level) and different function presents a positive effect on the integration of "sustainability". Facing to ideal model of "sustainability" integration, it is necessary to support a global collaboration as well as local information flow circulations between these three levels. This would contribute to ensure the efficient decisional information flows transfer through the whole company.

\section{Practical requirements taken from the industrial case "Eco Circle" of Quiksilver}

Quiksilver is one the world's leading outdoor sports lifestyle companies, which designs, produces and distributes a diversified mix of branded apparel, footwear, accessories, snowboards and related products. Quiksilver joined the "convergence" project to codevelop a systemic navigation approach to integrate sustainable issues into its activities. To highlight industrial practical requirements and consolidate our proposals, some interviews with corporate stakeholders were conducted. These interviews focused on a corporate environmental program named "Eco Circle" that integrates environmental aspects into the design process.

\subsection{The case study deployment method?}

\subsubsection{Aim}

The objective of these interviews was to understand current internal processes (Top managers, back office, design, marketing, operation and sellers) and the corporate environmental program (such as the topic, preparation, process and tools development). Centered on the "Eco Circle" program, this study carefully analyzed each node to deploy the environmental program, from top managers to designers and including some external stakeholders. A network of Quiksilver activities has been realized that highlights the knowledge streams among different stakeholders.

\section{- Interview support}

At first, to avoid miscommunication and misunderstanding in later interviews, some corporate context analysis and glossary preparation were conducted to establish a "common language" with interviewers.

To ensure quality of feedback, a questionnaire was prepared before the interviews were launched. This questionnaire included four sets:

- The daily work of interviewees. This part focuses on the position of the interviewee (for example the general management, management, and operational work), their responsibilities 
(missions and objectives), and the working process (decisional flow and related tools). This set also registered the reason and nature of collaboration with other functions.

- The position and role of each stakeholder in the environmental program.

- The links between daily classic tasks and environmental activities. These links include the supports used to integrate environmental issues into classic work and the type of decisions taken. In addition, the relationship between environmental profits and other success indicators was registered.

- Their opinions of current environmental activities embedded into their daily work. Such as what is the idea activity? What are the gaps between the actual situation and the idea model?

- Interviewees

In order to ensure data quality, according to the decision pathway of the company, this interview was addressed to the delegate of each internal function as well as the different hierarchy level agents (including top managers, managers of each section, designer and end operational people of each function). Overall, 28 interviews were conducted. The following table synthesizes the list of interviewees. Table 1

\subsection{Quicksilver's sustainable development management}

Since 1999, the Quiksilver Group has been working in the background, under the slogan “Don't Destroy What You Came to Enjoy", to protect environments through a host of initiatives ranging from eco-design and environmental management to awareness-raising events and partnerships with various associations. In 2005, the company founded the "Quiksilver Foundation", which bases its action on environmental, educational, health and youth-related projects in order to contribute to sustainable development worldwide.

According to this corporate strategy and the need for innovation, an internal program named "Eco Circle", was launched in the European branch to integrate eco-design aspects into the design process.

Table 1

The interviewee list for the case study.

\begin{tabular}{ll}
\hline Top managers & Chief operational officer \\
& Human resource director \\
& Sustainable development director \\
Back office & Sustainable development manager \\
& Communication director \\
& Financial controller \\
& Lawyer \\
Design & Design directors (2) \\
& Innovation director \\
& Stylist designer \\
& Graphic designer \\
& Design assistant \\
& Brand manager \\
Marketing & Marketing director \\
& Customer service \\
Operation & Operational planning \\
& Quality \\
& Resource office \\
& Production \\
Commercial administration & Retail network manager \\
Cellers & Commercial director \\
& Commercial assistant \\
& On line commerce \\
& Commercial analyst \\
&
\end{tabular}

\subsection{Quicksilver's "Eco Circle" program}

This program is headed by the Sustainability \& Innovation unit (S\&I unit) and the product manager. The S\&I unit encouraged and coordinated the integration of environmental aspects into the design process that was supervised by the product manager. Several external stakeholders were involved in this program in order to respond to program specifications. The aim is to reduce the use of raw materials, improve recycling performance and balance environmental and economic results.

Fig. 3 presents the organization of the "Eco Circle" project within Quiksilver. This organization is based on phases and information flows as detailed below.

- Competencies and information flows

A- Sustainable development, Quiksilver culture and organization

B- Technical knowledge, innovation, project management

C- Objective to "innovate" and time allocation

D- Combination of A \& B and strategic objective

E- Project specification

F- Product development expertise

G- Product development specific expertise

$\mathrm{H}-$ Eco technology, innovation, water management, environment

I- Quiksilver culture, "surf attitude", diffused expertise

J- "Surf attitude", customer knowledge

K- LCA expertise, HR (consultant)

L- Eco-design expertise, sustainable development, LCA, HR

(Prof. and students)

M- Funds

$\mathrm{N}$ - Innovative solutions (products, process, organization)

formalized in the "innovation catalog"

O- Solution validation and resource allocation

P- Eco-designed products

Q- Product environmental information

R- Conferences, seminars

S- POS advertising

T- Information on sustainable development and ecodesign - (DVD)

- Phase 0: initialization phase - sustainability \& innovation unit creation

The Sustainability \& Innovation unit was constituted by an external innovation consultant and the Corporate Sustainable Department (CSD) of Quiksilver. This collaboration was motivated by the chief executive officer under a corporate mission of "innovation development". The specific knowledge provided by the external consultant, such as innovation and project management, and the corporate situation by the CSD, such as the sustainability definition and internal organization, were brought together to fulfill the mission, to "innovate".

- Phase 1: Preparation phase - Definition of objectives and mobilization of resources

The Sustainability \& Innovation unit brought a product manager into their working meeting to define a product category for ecodesign. A snowboarding jacket for the new winter collection was chosen. After studying some related situations, such as the main functional requirements, the company's skills, relationships with suppliers and some internal constraints (Typically, the schedule and cost), they defined four major environmental improvement targets:

- Optimizing material use; 


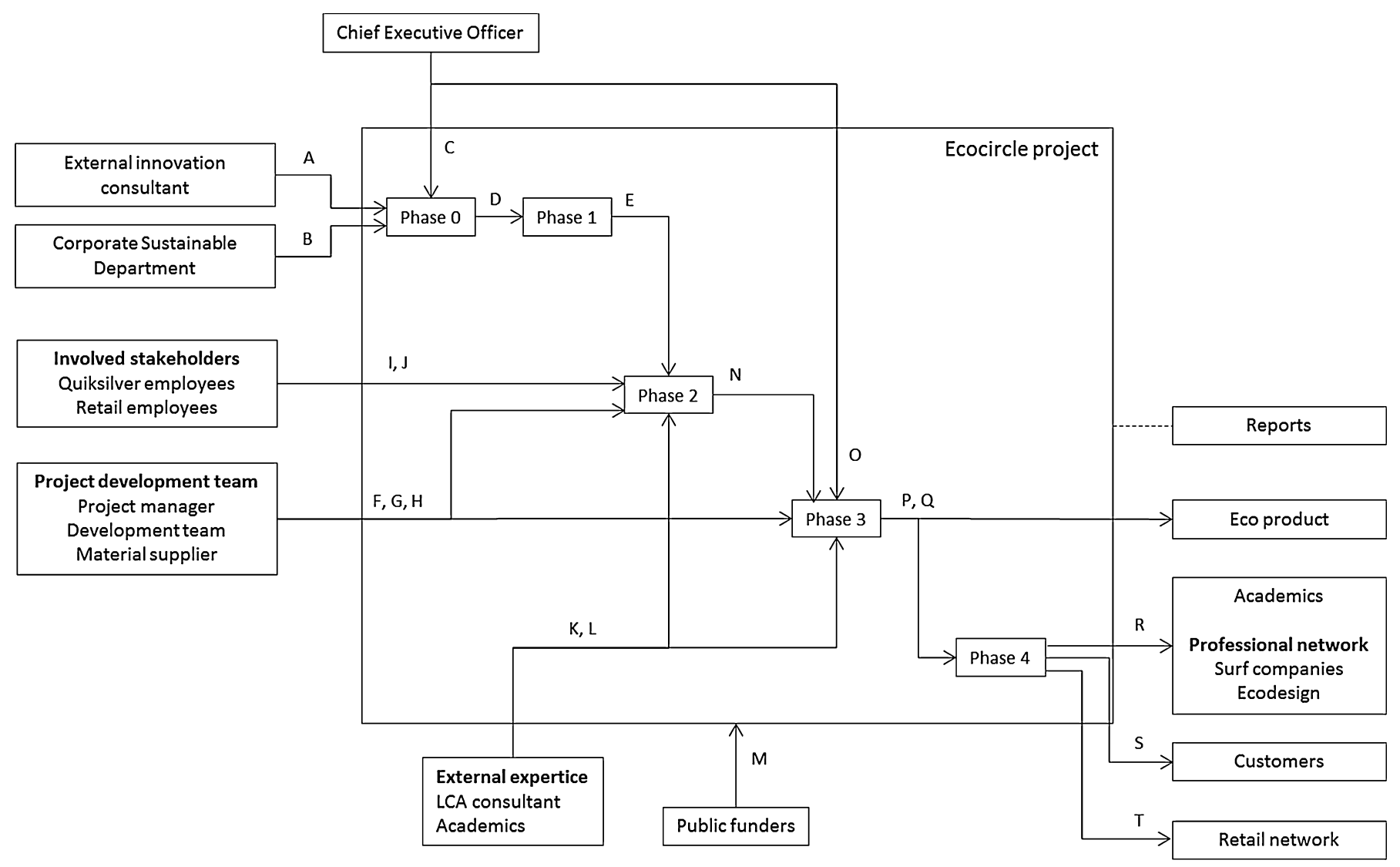

Fig. 3. "Eco Circle" implementing and resource transfer model.

- Using recycled and/or recyclable materials;

- Focusing on recycling;

- Measuring the product's life cycle performance.

Depending on these targets and corporate capabilities, the related environmental methods and tools were selected or developed to prepare the real initiative through the design process. Shortlists of avoidance materials and components were identified to optimize the use of materials. A checklist and a template for collecting and verifying the supplier's data had to be developed in order to measure the recycling situation; and a simplified LCA was selected to adapt to the initiative's needs. Besides the above, a requirement and environmental profit dashboard and a skill validation process were prepared to monitor the achievement: Table 2

- Phase 2: Launching phase - Internal training and innovative generation

Once the resources had been mobilized, several series of internal training were provided by external experts. Those sessions were delivered to every internal stakeholder involved in the project. After the creation of this common knowledge basis, the Sustainability \& Innovation unit supervised a brainstorming that allowed a mix of specific knowledge and generated several innovative items, which were formalized in an "innovation catalogue". It should be noted that a large amount of technical, business and organizational innovations were formulated during this brainstorming, some of which were not in line with pre-defined targets.

- Phase 3: Eco-design and prototype - Reaching product objectives
After some negotiation between the Sustainability \& Innovation unit and top managers, the design process began. There was close collaboration between the product development manager and the S\&I unit. The S\&I unit asked the project team to update the "product specification" to be completed by four environmental targets. Depending on these targets and the selected eco-design methods and tools, the design team generated the technical solution to resolve them. Due to the consideration of a new recycling technology, a material supplier was also involved to contribute to

Table 2

Resource mobilization for "Eco Circle" program.

\begin{tabular}{|c|c|c|}
\hline Project Requirements & Stakeholder involved & Specific knowledge \\
\hline $\begin{array}{l}\text { Eco-design training } \\
\quad \text { for the project team }\end{array}$ & $\begin{array}{l}\text { University of } \\
\text { Technology of } \\
\text { Troyes } \\
\text { External consultant } \\
\text { (EVEA) }\end{array}$ & $\begin{array}{l}\text { Pedagogy and eco-design } \\
\text { expertise, sustainability } \\
\text { and LCA. } \\
\text { LCA expertise }\end{array}$ \\
\hline $\begin{array}{l}\text { Life Cycle Analysis } \\
\text { expertise }\end{array}$ & $\begin{array}{l}\text { External LCA } \\
\text { consultant (EVEA) }\end{array}$ & LCA expertise \\
\hline $\begin{array}{l}\text { Product development } \\
\text { expertise }\end{array}$ & $\begin{array}{l}\text { Project manager } \\
\text { Project development } \\
\text { team } \\
\text { Material supplier } \\
\text { (TEIJIN) }\end{array}$ & $\begin{array}{l}\text { Project development } \\
\text { expertise } \\
\text { Specific product expertise } \\
\text { Recycling technology } \\
\text { Environmental knowledge }\end{array}$ \\
\hline $\begin{array}{l}\text { Funding } \\
\text { requirements }\end{array}$ & $\begin{array}{l}\text { Public funding } \\
\text { (ADEME and } \\
\text { Aquitaine region) }\end{array}$ & Funds \\
\hline $\begin{array}{l}\text { User review } \\
\text { requirements }\end{array}$ & $\begin{array}{l}\text { Some Quiksilver } \\
\text { back-office } \\
\text { employees } \\
\text { Retail shop } \\
\text { employees }\end{array}$ & $\begin{array}{l}\text { Quiksilver and "surf" culture } \\
\text { User/customer viewpoint }\end{array}$ \\
\hline
\end{tabular}


studying the final performance of the product. Some external experts used alternative supports to measure the environmental performance of the new technical solution on a life cycle perspective. During the design phase, the S\&I unit and product manager coordinated the information flow and ensured communication between the different stakeholders.

Finally, the design team developed 6 sub-models to optimize the use of materials and components, such as zips, sewing, cut lines. Also, the design team took a particular overview of the product dismantling process to ensure final recyclability. The documentation was registered all "eco-design" experiences and all related process and activities.

- Phase 4: Industrialization and valorization - eco-designing communication material and promoting the program

The eco-designed packaging and some communication materials were specified in order to contribute to the end-of-life performance, such as recycled materials for packages, point-of-sale display (POS), no-varnish package, extension of display materials.

Finally, communication was issued to the European retail network to promote the "Eco Circle" program and eco products. Some ads appeared in several stores and the international press. An operation was also held in 15 European stores, collecting customers' old clothes and giving them a discount for any eco product bought.

\subsection{Feedback and requirements from the "Eco Circle" program: key issues}

The implementation of the "Eco Circle" provides a great initiative for environmental integration into the company. At product level, some holistic analyses were conducted to identify a priori some environmental indicators. Then depending on the selected indicators and knowledge about the case study, several simplified methods were identified. In addition, an internal seminar was organized to prepare the program launch and share general information about eco-design. Designers and a supplier were selected as the principal project partners. Some collaboration with external environmental consultancy as well as internal environmental analyses was conducted to analyze the environmental issues. Next, the marketing and commerce teams were involved to communicate the environmental benefits and extend this into the business domain. At the end of the project, Quiksilver had obtained some environmental competences and experiences which will provide a useful base for future improvements. This project integrated a general environmental consideration into the corporate process. Today, the company has reached leader status in the field of surf and snow eco-design wear, and has frequently been invited to professional or academic conferences to present its benefits.

Comparing this industrial case study with the ideal integration model that was discussed in the previous section, the authors identified some points that could and need to be improved:

Although this program was approved by top managers, there was a lack of strategic holistic analysis: a lack of a contextualization analysis (economical position, corporate politics, environmental and social priorities) to identify suitable local objectives, including the selection of product parameters and environmental topics. Ideally, this analysis needs to be considered at that level. This should involve all possible stakeholders to identify the global tendency that the process will generate. During the "Eco Circle" program, R\&D department played a major role. However, advice coming from the marketing, commercial, communication departments and the final customers was insufficient. For the authors, the contribution of the commercial department should encourage and motivate continuous environmental improvement, providing a more balanced process. Without this contextualization analysis, it was difficult for the corporation to integrate environmental elements into their action plan.

Furthermore, their analysis shows a lack regarding the measurement of the performance system, which links the strategic tendency to environmental implementation targets. As a consequence, the company could not evaluate and measure the contribution of environmental improvement to global corporate development. This lack of performance measurement led to an arbitrary choice regarding innovative solutions and improvement targets. During the "Eco Circle" program, there were neither quantitative nor qualitative objectives nor any performance indicators to measure program success. The program could be considered as an "open loop" system which does not define any "feedback system": from customers to the R\&D department for instance (to measure improvements). In this situation, the "innovation catalog" and eco-design report were not diffused and reused in the company.

There were also no clear resource allocations for the "Eco Circle" project. There was a lack of collaboration planning among the different internal functions to take maximum advantage of the environmental improvements. Ideally, at the beginning of such a program, a global reflection should be conducted in order to allocate and plan the resources that could improve the final results. For instance, the communication department could be integrated at the early stage of the process.

Considering the positive aspects and shortcomings mentioned by the authors regarding the Eco Circle case study, the following section formulates the proposal of the Convergence project.

\section{The proposal of the convergence project}

\subsection{Development needs}

The above literature review and industrial case study show that an optimized circulation between the three different levels identified (strategic, tactical and operational) could improve the integration of environmental issues in the company. However, there are several major gaps between the ideal integration model and the current company scale. At strategic level, the company needs a legible and quantitative method to evaluate its global situation and development tendency. The study also showed its holistic approaches were not easily conducted: a global approach involving multi-stakeholders is necessary to create the relationship between value creation and sustainable activities in-company. At tactical level, a global and overall approach is also necessary to identify a sustainable trajectory (with a series of selected methods), in accordance with strategic objectives and the complex and dynamic changeable corporate context. At operational level, collaboration between multi-domain activities should be improved by a dynamic and flexible way of exchanging information. This would support the use of the environmental methods and tools defined by managers. The dynamic and flexible properties of the company IT system would be suitable for adapting the process to the various changing design contexts. A systemic approach is thus needed to ensure collaboration between all three levels and to allow an efficient transfer of decisional information flow in-company.

As a consequence, a holistic, overall and systemic approach will be proposed to navigate environmental integration in-company. In the authors' view, this approach must be totally embedded in the company, and will include three different modules: the strategic module, the tactical module and the operational module. In each module, a list of actions is instituted to resolve the previous problematic issues. The interface and some related interactions will then be set up to ensure circulation and collaboration between the different modules. 


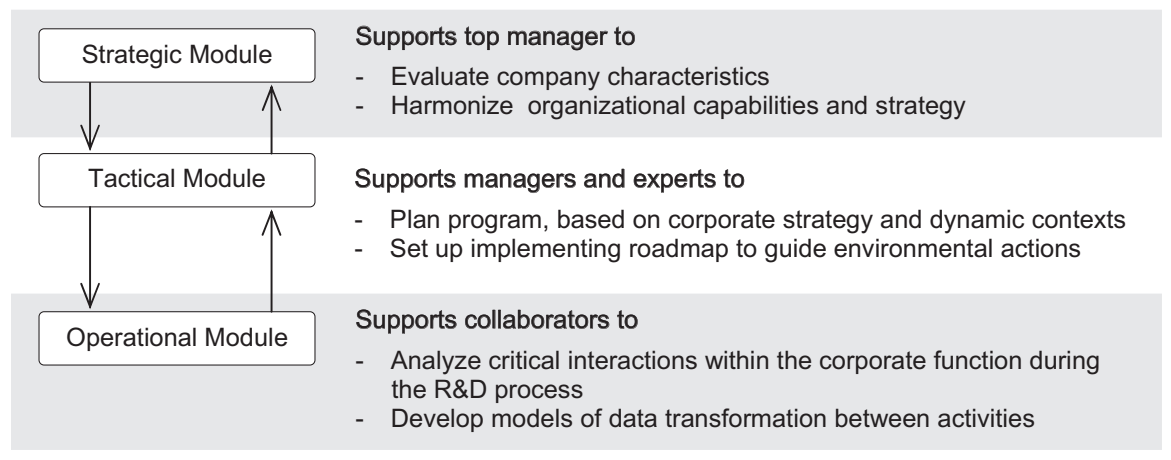

Fig. 4. The principal framework of "convergence" proposals.

\section{2. “Convergence" proposals}

Depending on previous needs summarized in chapter 4.1, the Convergence proposal is built on three complementary modules: strategic, tactical and operational (cf. Fig. 4). This proposal supports the company in adopting a transversal and holistic approach toward sustainability

\subsubsection{The strategic module}

The strategic module is composed of four main modules: strategic analysis, strategic choice, strategic deployment and a transversal module to manage performance.

The strategic analysis module proposes assisting the decisionmakers to collect large amounts of information to identify the current resources and organizational capabilities of the extended company. Two sub-modules support this objective: First, the "Capabilities" sub-module is dedicated to detecting the internal and external capabilities and second, the "Governance" module, detects the maturity level of corporate governance.

- The "Capabilities" sub-module is dedicated to the identification and capitalization of internal and external resources. It identifies related stakeholders and detects their own capabilities, their needs and wants and their core competencies. Finally, a map of actual available resources could be drawn to respond to the corporate strategic objectives.

- The "Governance" sub-module characterizes the company's maturity along two axes: sustainability integration and intangible integration into the corporate governance. Alternative strategies are proposed in the "Choice" module regarding this classification (service strategy, law compliance, and industrial ecology). An example would be the Porter's (Porter E., 1979) three generic strategies (cost leadership, differentiation or focus) that are determined by competition. Conversely, Mauborgne and Kim propose the blue ocean strategy ${ }^{3}$ that consists of creating new markets thanks to innovation.

The combination of the "Governance" and the "Capabilities" sub-modules and the extended scorecard can support the strategic analysis with a widened range of information that completes the classical marketing or financial analysis.

- The strategic choice module accompanies top management in identifying sustainable strategies. The aim of this module is to classify some strategic choice alternatives. Alternative strategic choices come directly from the analysis module. In fact, all needs and wants of the multiple stakeholders are considered as potential strategic tendencies. The strategy must be constructed for each potential strategic objective and represent strategic alternatives. Some innovative strategies will also be proposed based on several maturity levels of the company, which are determined in the analysis module. Next, the strategic choices are ranked according to different criteria: sustainability of the choice, significance of the stakeholders, and company capabilities. The strategic choice module provides outputs: the classification of alternatives and a clear definition of the objectives associated to key strategic indicators (KSI).

- The strategic deployment module allows objective validation, formalization of the strategic roadmap and resource allocation to fulfill strategic objectives. The success or failure of strategic deployment depends on collaboration between strategic and tactical levels at this timing point. Roadmap creation will be detailed in further work.

- The transversal management module consists in two performance measurement systems with different time horizons and destinations. This provides a multi-view picture of the overall performance of the firm.

The first one is dedicated to measure the performance of operational strategy. It consists of a multiple level set of Key Indicators: KSI for the strategic, KTI for the tactical and KOI for the operational levels. These indicators support information circulation (cf. section 4.2.4) and performance measurement along the deployment of strategy into the company.

The second measurement system allows top management (and shareholders) to have an overview of the whole company value creation system. Each value creation factor (such as knowledge, innovation, and trend) is evaluated by a set of intangible capitals. This also provides an 'intangible profile' of the company with its differentiation factors (such as a long term customer relationship or a great innovation capability).

\subsubsection{The tactical module}

The tactical module supports department managers and experts in formulating an achievable roadmap to respond to strategic and project needs. This roadmap defines some implementing trajectories, step by step, depending on available resources. These trajectories gather a chain of environmental methods and tools to pilot the generation of environmental improvements. To ensure "suitability", this tactical module:

- Prepares a database, which registers existing environmental methods and tools. For each method or tool, there is a series of

\footnotetext{
${ }^{3}$ Website of Blue ocean strategy: http://www.blueoceanstrategy.com/.
} 
uniform criteria to evaluate its characteristics and its relationship with others. Characteristics do not only focus on engineering issues, such as main functions, objectives and input/output data, but also take into account some operational indicators (treatment duration with standard competence. level normal executive cost and the training fee). Some characteristics ensure the identification of relationships, for example, the uniform I/O list could support the establishment of a method chain, and the constraints of each method might indicate collision with other methods.

- Analyses the final goal to initiate the trajectories. Depending on the different types of need, this goal may come from the strategic tendency and requirements of capital movement, or from the special needs of the project. Based on this database, this module initializes all possible trajectories (with the selection of related methods and tools) to respond to the final goal. In order to identify which trajectory's group is more suitable, some additional checks should be implemented:

- Engineering collision check: to respond to multi-objectives, some parallel trajectories will be launched at the same time. Therefore, the "trade off" risk analysis should be conducted to evaluate the capacity of implementation. "Trade off" means two methods cannot be used in parallel. This "trade off" might appear between different improvable objectives (for example, the collision between modularity design and minimum waste).

- The operational sharability check: to reduce the operational cost and encourage implementation, the maximum sharability of inputs is preferable. This additional check will establish the priority between number of inputs and number of required methods.

- The operational complexity check: the different competences and data localization make the operational cost and complexity vary. Other corporate strategies are also influenced by the operational environment. So this complexity check should be conducted to make a more suitable choice.

- Depending on previous trajectories and some additional checks, organizes and allocates resources to establish a suitable roadmap, which defines the objective achieving process, step by step, with a series of selected methods.

\subsubsection{The operational module}

The operational module provides a flexible and dynamic framework based on federation of tools, which supports the design process deployment in line with the defined tactic. The aim is to optimize the interactions needed between the product design process and environmental engineering activities (supported by tools, software). Depending on the defined action plan, this module analyses the data interaction between environmental and product design activities and helps to perform these activities in line with the existing working environment (IT system: Product Life Cycle System for instance, working flow and collaboration facilities between specific services.). Activities sequencing is optimized by an efficient interoperability between the product designer's tools and the environmental tools. Some "mappings" are defined and implemented to federate tools. The mappings are obtained by formalizing the links between the data input needed to perform the given activities and the data output created in each activity. The design process is therefore defined and deployed progressively. This operational process is flexible to changes and allowing dynamic data exchanges between the activities involved. The proposal verifies the following properties:

- Adaptability to different contexts of tools defined by the tactic;

- Use of any available data needed during the deployment of the design process;
- Linking the global environmental parameters to the local product design domain parameters

Several stages are involved in this module:

- Stage one: provides a systemic vision of information $\mathrm{I} / \mathrm{O}$ connections between activities involved.

- Each method selected in the tactical module involves several activities. The aim of this first stage is to connect the different activities, in order to deploy the design process as effectively as possible.

- Stage two: definition of the information model's transformation between two given models.

- The information model's transformation supports the mapping between data models to federate them.

- Stage three: initialization of the design process, covering the various methods defined by managers.

- Stage four: integration of environmental into each local activity.

The integration of environmental parameters (as well as socioeconomical parameters) into the designer's activities can be facilitated by this proposal (Rio et al., 2013). One of the difficulties encountered in the operational module is indeed to give capacity to local designers to take into account the environmental parameter when performing their activity. Integration will be effective when:

- Designers understand the link between the parameter they are mastering and the environmental parameter that is dependent on its variation;

- A support provides the direct link between the parameter they are mastering and the environmental parameter that is dependent on its variation. This support may be based on a federative solutions (information systems level) coupled to a specific plug-in in product designer's software. In some cases, there is no need to develop a plug-in. For example, some local environmental tools can be used as an "environmental analysis results" viewer: the sustainability module in CAD software for instance. This support enables designers to reiterate their choice effectively.

\subsubsection{The interface between the three modules to improve general coherence}

To improve the integration of environmental issues and avoid misunderstanding, a systemic approach is necessary. In addition, the systemic approach should have the capacity to ensure collaboration between the different hierarchy levels and to provide an efficient transfer of decisional information flow in the entire company. To respond to this issue, the "Convergence" project proposal provides some information flows among the three modules, known as "interfaces".

\section{- The interface between strategic and tactical modules}

The principal transfer between the strategic module and the tactical module aims to diffuse the strategic decision and related performance indicators. Once the strategic module has broken down the global tendency into compositional strategic targets, these targets and all related analyses and supports (such as data, situation analysis, initial position and movement of capital) will be inputted into the tactical module to guide the method's selection. Furthermore, key strategic performance indicators (KSI) are established and translated to observe and guide the implementation.

Depending on the received strategic targets and constraints, the tactical module defines the roadmap to ensure the final 
achievement. This definition should be transferred to the strategic module to ask for a final validation. As a complement, in line with each KSI, a series of key tactical performance indicators (KTI) are ideally defined to measure the processing achievement of KSI. Finally, during the implementation, the KTI score is continuously reported to the strategic module to modify the KSI score.

To establish the initial company evaluation and follow the continuous updates, the tactical module provides the related data, in particular professional data on sustainable development, to the strategic module. The tactical module may also be involved in the decision process to provide propositions (for example, the tactical module can show if there are methods available to resolve a given issues).

- The interface between tactical and operational modules

The tactical module transfers the defined roadmap and all related operational documents to the operational module. This roadmap includes the selected environmental methods and tools, the timing requirement of launches, needs of inputs and types of outputs. This roadmap also defines the roles, responsibilities and actions of each stakeholder involved at this step. Depending on this roadmap, the operational module may perform the real activities and processes to implement the program. Finally, in order to improve each KTI level, a list of key operational performance indicators (KOI) is created. The report of KOI results provides real feedback to modify and update the tactical roadmap.

Conversely, to ensure the dynamic generation of design ideas, which includes some autonomy activities that are not yet included in the roadmap, the operational module has the capacity to transfer the newly generated ideas and solutions to the tactical module. This transfer updates and completes the corporate method database. Then, if this new idea has visible effects on the operational condition, the transfer may generate some modifications in the roadmaps.

\subsection{Applicable scenarios}

In line with the previous presentation of the three modules and interactions, some applicable scenarios are proposed to transfer the decision flow, indicators and related information and competences. "Top down" presents one applicable scenario, which defines how to plan some implementable activities, in order to respond to strategic requirements. Conversely "bottom-up" presents how the actual operational environment (process, technical possibilities) affects strategic decision-making. Finally, "middle-two sides" presents how to integrate some additional sustainable issues in the company. This scenario may appear in some emergent situations, when answering to specific requirements, for instance.

\subsection{1. "Top-down" scenario}

The "top-down" scenario illustrates the proposed knowledge and decisional ordering process for integrating all selected eco-design activities into the company, from global strategy (strategic level) to practical collaboration (operational process). Fig. 5

At first, the strategic module proposes an overview and a scoring system to present the corporate context, requirements, and corporate needs. Depending on the above quantified results, the strategic module establishes a global sustainable tendency, which will be broken down by some compositional strategic targets. Then the strategic description of targets and additional analyzed data are translated to the tactical module. According to this strategy, the tactical module explores all possible trajectories in the sustainable methods database. By the iterative simulation of the feasibility and the capacity to implement of the trajectories, a corporate acting roadmap to conform the operational constraints and needs above targets is planned and formulated. This roadmap defines the shortterm and long-term action plan, responsibility and actions of related corporate functions, schedule, theoretic information flow and some related supporting activities (Ex: recruitment or training). Lastly, the operational module transfers the roadmap as a

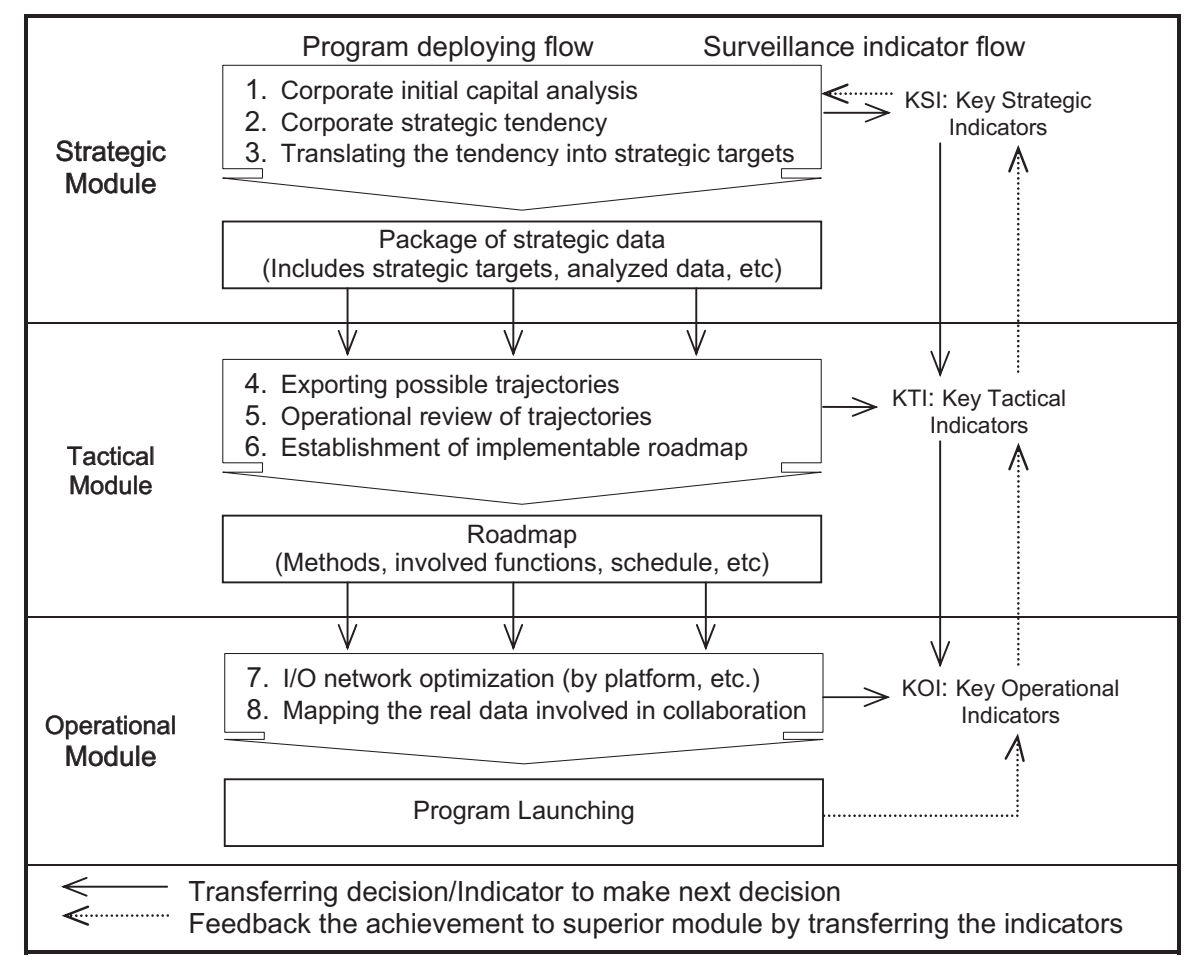

Fig. 5. Working flows and decisional transfers of the "top-down" scenario. 


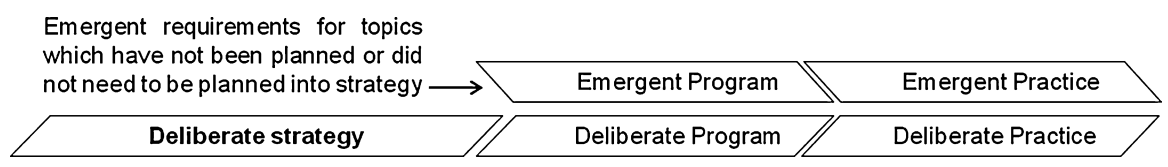

Fig. 6. Macro-work flow for emergent requirements.

detailed practical working flow. The working flow breaks down the required actions into some real working activities. It arranges and optimizes the I/O network of all activities and integrates them into the actual working process of the company. Additionally, some modifications required to optimize this integration of the actual process will be analyzed. To ensure the information circulation between the three different levels and to verify the status, some interfaces between the three modules have been identified, such as translation from the strategic indicators to operational control indicators.

In parallel, in order to observe and follow the program development, a series of surveillance indicators can also be established in each module. At strategic level, depending on the need of the capital movement, the key strategic indicators (KSI) are defined. This set of indicators is translated to the tactical module. The tactical module defines its key tactical indicators (KTI) to measure the achievement of each program activity. The KTI should also create quantified links with the related KSI. Depending on the KTI, the operational module defines the KOI (Key operational indicators) to exactly measure the performance of the daily work occurring in each activity. Finally, after the program launch, a hierarchical indicators report system between KOI, KTI and KSI gives some feedback about the practical situation to the strategic level, which consequently measures the final achievement reached.

\subsection{2. "Bottom-up" scenario}

The "Bottom-up" scenario presents how operational practice affects and implements strategic decision-making. In line with the development of new technology and knowledge, the company's capital is consequently continuously modified to reflect this update.

This scenario starts from the operational module, and begins when new knowledge and new competences are detected. These new knowledge and competences are then transferred to the tactical module, which registers them in the method database. If this occurs, the update can be marked as a new achievement. In this case, the strategic module modifies the corporate capital scores to reflect this update in the corporate situation.

\subsection{3. "Middle-two sides" scenario}

The "middle-two side" illustrates the scenario that resolves the operational disturbance from some emergent requirements. The emergent requirements mean that the company or certain projects are required to treat some sustainable topics which have not yet been planned in-company. These requirements also present particular needs for some neglectable topics from the strategic level. For example: specific requirements of dismantling process for the product category, which is outside the legislation area. If necessary, the treatment of these topics may answer requirements. Furthermore, this can update and complete the corporate

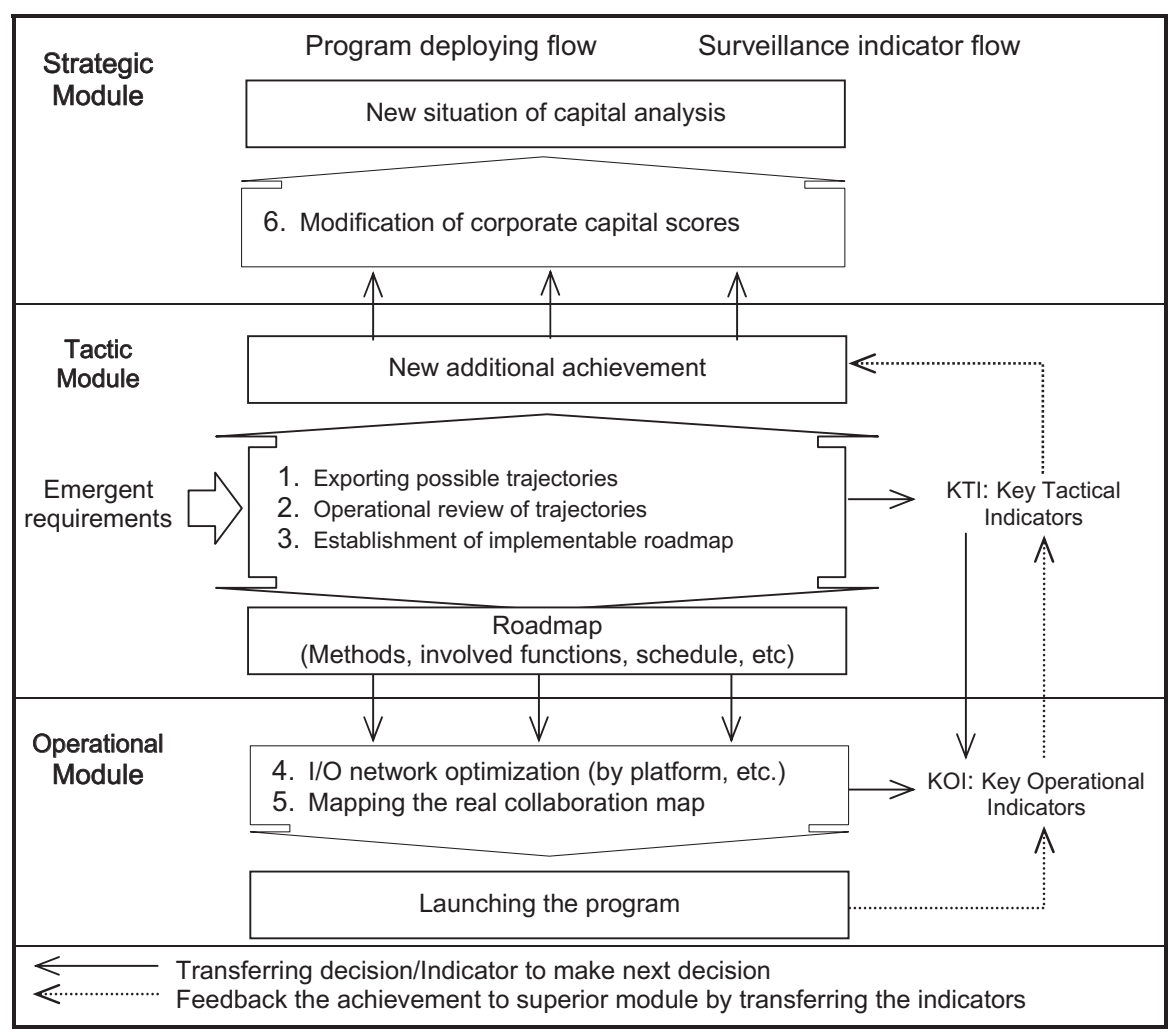

Fig. 7. Work flow and decisional transfer of "middle-two sides" scenario. 
knowledge and competence level, which may affect future strategic decisions. Fig. 6

This scenario starts from the tactical level. The managers decide if the company needs to answer these requirements. If yes, the tactical module analyzes the needs to explore the applicable direct methods or trajectories. Depending on the actual knowledge situation, the tactical module identifies an adapted planning. This plan will be transferred to the operational module to map the information exchanges needed to facilitate collaboration among designers. Finally, following the surveillance indicator system, the tactical module synthesizes the new additional sustainable achievements. Based on this achievement, the strategic module modifies the corporate capital scores to reflect this update of the corporate situation (knowledge level, experience). Fig. 7

\section{Conclusion and future work}

This paper states that a better circulation between the different functions in company could improve the integration of sustainable issues. As a first step to explore this assumption, authors have decided to focus on the environmental aspects of sustainability. Based on a literature analysis and an industrial investigation, they have found that there were several major issues to consider for reaching the ideal integration model from the current situation. Therefore a navigation system has been proposed to provide a holistic, overall and systemic support to companies willing to integrate environmental concerns in their processes. The main outcome of this paper is to present this navigation system, composed of three complementary modules: strategic, tactical and operational. The three modules cover the total corporate activities from global corporate development level to product realization level. Each level is addressed to different and complementary stakeholders in the company, in line with their own activity and expertise. This paper has illustrated through an industrial case study the principle and working framework of each module, involving calculation methods, roadmaps and IT developments. In addition, the interactions between each module have been defined at their interfaces to establish the coherence between the three modules. The modules are using complementary metrics and indicators, such as key strategic indicators, key tactical indicators and key operational indicators. Finally, three applicable scenarios, "topdown", "bottom-up" and "middle-two sides", have been presented and illustrated to explain the navigation system's work flow and macro-structures.

This project is part of a French National Research Agency (ANR) project named Convergence, The proposed navigation system presented in this paper is now being tested by the Quiksilver Company. The results of experiments and the development of the system will be the object of further publications. The project planes to disseminate the navigation system to other industries. This will be managed by the IFTH, as project partners.

\section{Acknowledgment}

The authors wish to thank the National Research Agency for funding the Convergence project. This paper presents the collaborative work of three $\mathrm{PhD}$ students involved in the project, supported by four laboratories (CREIDD, GSCOP, LSIS, and IAE Lyon) and two industrial partners (Quiksilver and IFTH).

\section{References}

Airbus, 2008. Airbus Corporate Answer to Disseminate Environmental Management System. http://www.airbus.com/company/environment/documentation/.
Allee, V., July-August 2000. Reconfiguring the value network. Journal of Business Strategy 21 (4).

Azar, C., Holmberg, J., Lindgren, K., 1996. Socio-ecological indicators for sustainability. Ecological Economics 18, 89-112.

Baret, P., 2006. l'évaluation contingente de la performance globale des entreprises: une méthode pour fonder un management sociétalement responsable ?. cited in Berland Mesure de la performance globale des entreprises.

Baumann, H., Boons, F., Bragd, A., 2002. Mapping the green product development field: engineering, policy and business perspectives. Journal of Cleaner Production 10 (5), 409-425.

Bieker, T., Gminder, C.U., 2001. Toward a Sustainability Balanced Scorecard. Oikos Summer academy. Pages 14, cited in Capron and Quairel, 2006.

Blessing, L.T., Chakrabarti, A., 2009. DRM, a Design Research Methodology. SpringerVerlag, London, ISBN 978-1-84882-586-4. http://dx.doi.org/10.1007/978-184882-587-1.

Botsmann, R., Rogers, R., 2011. What's Mine Is Yours, How Collaborative Consumption is Changing the Way We Live. Harper Collins, ISBN 978-0-00739591-0.

Bovea, M.D., Pérez-Belis, V., January 2012. A taxonomy of ecodesign tools for integrating environmental requirements into the product design process. Journal of Cleaner Production 20 (1), 61-71.

Brezet, J.C., Van hemel, C., 1997. Ecodesign - A Promising Approach to Sustainable Production and Consumption. UNEP, United Nations Publication, USA.

Buclet, N., 2011a. Le territoire, entre liberté et durabilité. Presses Universitaires de France, ISBN 978-2-13-057925-0

Buclet, N., 2011b. Écologie industrielle et territoriale, stratégies locales pour un développement durable. Presses Universitaires du Septentrion, ISBN 978-27574-0331-0.

Byggeth, S., Hochschorner, E., 2006. Handling trade-offs in eco design tools for sustainable product development and procurement. Journal of Cleaner Production 14 (15-16), 1420-1430.

Capron, M., Quairel, F., June 2006. Évaluer les stratégies de développement durable des entreprises: l'utopie mobilisatrice de la performance globale. Revue de l'organisation responsable $1,5-17$.

Charreaux, G., Desbrières, P., 2001. Corporate governance: stakeholder value versus shareholder value. Journal of Management and Governance 5 (2), 107-128.

De Bakker, F.G.A., Fisscher, O.A.M., Brack, A.J.P., 2002. Organizing product-oriented environmental management from a firm's perspective. Journal of Cleaner Production 10 (5), 455-464.

Donnelly, K., et al., 2006. Eco design implemented through a product-based environmental management system. Journal of Cleaner Production 14 (15-16), 1357-1367.

Erlandsson, J., Tillman, A.M., 2009. Analysing influencing factors of corporate environmental information collection, management and communication. Journal of Cleaner Production 17 (9), 800-810.

European Parliament and of the Council, Regulation (EC) No 1221/2009 on the voluntary participation by organizations in a Community eco-management and audit scheme (EMAS), 2009.

Freeman, R.E., 1984. Strategic Management: a Stakeholder Approach. Pitman, Boston.

Hallstedt, S., Ny, H., Robèrt, K.H., Broman, G., 2010. An approach to assessing sustainability integration in strategic decision systems for product development. Journal of Cleaner Production 18 (8), 703-712.

Hockerts, K., 2001. Corporate sustainability management - towards controlling corporate ecological and social sustainability. In: Ninth International Conference of Greening of Industry Network Bangkok. January 21-25.

Hillman, A., Klein, D., 2001. Shareholder value, stakeholder management, and social issues: what's the bottom line? Strategic Management Journal 22, 125-139.

IEMS, Integrated Environmental Management System Implementation Guide, EPAUnited states Environmental Protection Agency, 2000.

Iraqi, M., Kleiner, M., Roucoules, L., 2011. Model-based (mechanical) product design. MoDELS, 548-562.

Iraqi, M., Kleiner, M., Roucoules, L., July 2012. Tools interoperability in engineering design using model-based engineering. In: Proceedings of the 11th Biennial Conference on Engineering Systems Design and Analysis ESDA2012, France.

ISO International Organization for Standardization, Environmental ManagementIntegrating Environ - Mental Aspects into Product Design and Development, ISO/TR14062:2002(F), Geneva, 2002.

ISO International Organization for Standardization, Environmental management systems - Requirements with guidance for use, ISO14001: 2004, Geneva, 2004.

ISO International Organization for Standardization, Guidance on Social Responsibility, ISO/CD 26000, Geneva, 2008.

Johansson, G., 2002. Success factors for integration of eco design in product development - a review of state-of -the-art. Environmental Management and Health 13 (1), 98-107.

Johnson, G., Scholes, K., 2008. Exploring Corporate Strategy, eighth ed. - fourth French ed. Pearson Education, France, ISBN 978-2-7440-7276-5.

Jørgensen, T.H., 2008. Towards more sustainable management systems: through life cycle management and integration. Journal of Cleaner Production 16 (10), 1071-1080.

Kaplan, R., Norton, D., March 2001. "transforming the balanced scorecard from performance measurement to strategic management". Accounting Horizon 15 (1), 87-104.

Knight, P., Jenkins, J.O., 2009. Adopting and applying eco-design techniques: a practitioner's perspective. Journal of Cleaner Production 17 (5), 549-558. 
Lakemond, N., Berggren, C., 2006. Co-locating NPD? The need for combining project focus and organizational integration. Technovation 26 (7), 807-819.

Lu, S.C.-Y., Elmaraghy, W., Schuh, G., Wilhelm, R., 2007. A scientific foundation of collaborative engineering. CIRP Annals 56 (2), 605-634.

MacDonald, J.P., 2005. Strategic sustainable development using the ISO 14001 Standard. Journal of Cleaner Production 13 (6), 631-643.

Mathieux, F., Brissaud, D., Roucoules, L., Lescuyer, L., 2007. Connecting CAD and PLM systems with eco-design software: Current experiences and futures opportunities. In: International Conference on Engineering Design 2007, Paris, France, 31st of August.

Mercier-Laurent, E., 2009. Les écosystems de l'innovation. Lavoisier, ISBN 978-27462-2117-8.

Mitchell, R., et al., 1997. Toward a theory of stakeholder identification and salience: defining the principle of who and what really counts. Academy of Management Review 22 (4), 853-886.

Mougenot, C., Décembre 2008. Modélisation de la phase d'exploration du processus de conception de produits. Ecole Nationale Supérieure d'Arts et Métiers (pour une créativité augmentée $\mathrm{PhD}$ thèses).

Neely, A., 2007. Business Performance Measurement. Cambridge University Press, ISBN 978-0-521-85511-2.

Niemann, J., Tichkiewitch, S., Wesstkamper, E., 2009. Design of Sustainable Product Life Cycles. Springer, springer-verlag berlin heidelberg, ISBN 978-3-540-790815, 2009 edition.

Normann, R., Ramirez, R., July - August 1993. From value chain to value constellation: designing interactive strategy. Harvard Business Review, 65-77.

Normann, R., Ramirez, R., 1994. Designing Interactive Strategy: From Value Chain to Value Constellation. John Wiley \& sons, ISBN 0-471-95086-6.

Pahl, G., Beitz, W., 1996. Engineering Design: a Systematic Approach, second ed. Springer Verlag Edition, London.

Pardo, R.J.H., Brissaud, D., Zwolinski, P., 2011. Contribution to the characterization of ecodesign projects. International Journal of Sustainable Engineering 4 (4), 301-312.

Paviot, T., 2010. Méthodologie de résolution des problèmes d'interopérabilité dans le domaine du Product Life cycle Management. PhD thèses, Ecole Centrale Paris.

Porter, M.E., March-April 1979. How competitive forces shape strategy. Harvard Business Review, 137-145.

Pujari, D., Peattie, K., Wright, G., 2004. Organizational antecedents of environmental responsiveness in industrial new product development. Industrial Marketing Management 33 (5), 381-391.

Quairel, F., 2006. Contrôle de la performance et responsabilité sociale de l'entreprise (RSE). Comptabilité, contrôle, audit et institution(s).

Reyes T., Millet D. and Joan M, "Development of eco-design integration trajectories: two surveys and LCA case of study with a power distribution product" International Conference on engineering Design ICED'07, 28-31 August 2007, Paris.

Riel, A., Tichkiewitch, S., Messnarz, R., 2010. Qualification and certification for the competitive edge in integrated design. CIRP Journal of Manufacturing Science and Technology 2 (4), 279-289.
Rio, M., Reyes, T., Roucoules, L., 2011a. A framework for eco-design: an interface between lca and design process. International Journal of Engineering 4 (1) 121-126.

Rio M., Reyes T., Roucoules L, Toward proactive eco-design based on engineering and eco-designer's software interface modeling, International conference on engineering design ICED11, Copenhagen, Denmark, 15-18 August 2011b

Rio, M., Reyes, T., Roucoules, L., 2013. Toward proactive (eco) design process: modeling information transformations among designers activities. Journal of Cleaner Production 39, 105-116.

Robèrt, K.-H., et al., June 2002. Strategic sustainable development - selection, design and synergies of applied tools. Journal of Cleaner Production 10 (3), 197-214.

Rocha C. Silvester S., Product-oriented Environmental Management Systems (POEMS): From Theory to Practice - Experience in Europe, Project "Start IPP " Starting with the Integrated Product Policy, 2001

Roozenburg, N.F.M., Eekels, J., 1995. Product Design: Fundamentals and Methods. John Wiley \& Sons. ISBN-10: 0471954659.

Supizet, J., December 2002. Total Balanced Scorecard, un pilotage aux instruments L'Informatique Professionnelle Number 209, 15-20.

Siegenthaler, C.P., Braunschwig, A., Oetterli, G., Furter, S., 2005. LCA Software Guide 2005 - Market Overview - Software Portraits. ÖBU, Zurich, ISBN 3-908233-29-1.

Theret J.P. Zwolinski P., Mathieux F, Integrating cad, plm and lca: a new architecture and integration proposal, International Conference on Renewable Energy and Eco-Design in Electrical Engineering, Lille France, March 2011.

Unger, N., Schneider, F., Salhofer, St, 2008. A review of eco-design and environmental assessment tools and their appropriateness for electrical and electronic equipment. Industrial Ecology 5 (1-2), 13-29.

Vallet F., Millet D., Eynard B., "How ecodesign tools are really used - requirements list for a context-related ecodesign tool”, 20th CIRP Design Conference, Nantes France, 19 - 21 April, 2010

Wagner, M., 2007. On the relationship between environmental management environmental innovation and patenting: evidence from German manufacturing firms. Research Policy 36 (10), 1587-1602.

Yen, Y.X., Yen, S.Y., 2012. Top-manager's role in adopting green purchasing standards in high-tech industrial firms. Journal of Business Research 65 (7) 951-959.

Zhang F., Zwolinski P, “Optimized navigation system for eco-design management”, 12e Colloque National AIP PRIMECA, Le Mont Dore 29 March - 01 April, 2011

Zhang F., Zwolinski P, "Toward unified environmental activities in enterprise", Proceedings of the 12th International Design Conference DESIGN 2012, pages 1205-1214, Cravat, Croatia, 2012

Ziegler, A., Nogareda, J.S., 2009. Environmental management systems and technological environmental innovations: exploring the causal relationship. Research Policy 38 (5), 885-893. 